\title{
INTERNATIONAL JOURNAL OF CURRENT RESEARCH IN BIOLOGY AND MEDICINE
}

\author{
ISSN: 2455-944X \\ www.darshanpublishers.com
}

DOI:10.22192/ijcrbm

Volume 2, Issue 5 - 2017

\author{
Original Research Article
}

DOI: http://dx.doi.org/10.22192/ijcrbm.2017.02.05.003

\section{Medical management of Benign Prostate Hyperplasia: New insights}

\author{
*N.S. Neki, **Jaswinder Singh \\ *Professor, **Junior Resident, Department of Medicine, Govt. Medical College/ Guru Nanak Dev Hospital, \\ Amritsar, India, 143001 \\ Corresponding Author: Dr. Jaswinder Singh, Junior Resident, Department of Medicine, Govt. Medical \\ College/ Guru Nanak Dev Hospital, Amritsar, India, 143001 \\ E-mail:winjaz@gmail.com
}

\begin{abstract}
Benign prostatic hyperplasia (BPH) is a very common disease of elderly men. The development of effective medical treatment of $\mathrm{BPH}$ has resulted in decreased need for invasive surgical interventions lately. In the initial stage, watchful waiting and lifestyle modification may be sufficient. There are a few treatment options which are available for treatment of BPH. Various strongly designed placebo controlled clinical trials like the Veterans Affair study( VA) study and the PREDICT study have shown the value of treating BPH in general population with monotherapy using an alpha blocker. But there is some evidence of superiority of combination therapy with an alpha blocker and 5 alpha reductive inhibitors in patients of BPH with large prostate sizes. Some newer drugs like NX-1207 and GNRH agonists, and some new techniques like Intraprostatic toxin type- A have also been studied for their usefulness in BPH. All of these new treatment options have shown promise in initial research.
\end{abstract}

Keywords: Benign prostate hyperplasia(BPH),Alpha blocker, Lower urinary tract symptoms

\section{Introduction}

Benign prostatic hyperplasia (BPH) is a medical condition which is very prevalent among elderly male population. Twenty percent of males of age 40 years or more suffer from $\mathrm{BPH}$ and the prevalence of $\mathrm{BPH}$ increases to ninety per cent in 90 years old men .(1) About half of the men with BPH experience moderate to severe lower urinary tract symptoms. (2)The symptoms of BPH are collectively defined as lower urinary tract symptoms (LUTS). LUTS can be subdivided into obstructive and irritative symptoms. Obstructive symptoms include urinary hesitancy, straining, weak flow, prolonged voiding ,partial or complete urinary retention and urinary incontinence. The common irritative symptoms include urinary frequency, urgency, nocturia, dysuria, and decreased urinary void volume. (3). BPH is the primary cause of prostatic enlargement, which involves both the stromal and epithelial elements of the prostate. (4) $\mathrm{BPH}$ causes compression of prostatic urethra which leads to impaired voiding of urine. Histological picture of BPH shows discrete nodules, which are present in periuretheral zone of the prostate gland. Interestingly, the symptom severity in BPH does not always correlate with degree of prostatic hyperplasia. (5) Moreover, LUTS is not unique to BPH. These symptoms can occur in many urological and non urological diseases unrelated to BPH. F like prostate cancer, prostatitis, bladder cancer, bladder stones, overactive bladder (OAB), intestitial cystitis, and urinary tract infections LUTS. $(6,7)$ 
ISSN: 2455-944X

The American Urology Association (AUA) has given the scoring system for assessment of severity symptoms of urinary tract symptoms. The range of this score is from 0 to 35 . The severity of symptoms are graded into mild (0-7), moderate (8-19) and severe (20-25). (8)

Both static and dynamic factors contribute towards the development of bladder outlet obstruction (BOO) in patients of BPH (9). The enlarged prostate gland in $\mathrm{BPH}$ results in static obstruction, whereas the dynamic component is due to tension in prostate smooth muscles. The modifications of these two component are targets of medical management of BPH. (10). Studies have shown that the prevalence, severity, and dissatisfaction with LUTS increases with age. Moreover, dissatisfaction with the urinary tract symptoms increases with increasing severity of LUTS. Severity of LUTS is also associated with poorer health quality and a greater prevalence of a person's inability to perform daily activities. (11) $\mathrm{BPH}$ leads to considerable stain on healthcare of a country. In the year 2000, approximately 8 million health visits to physician offices in the US were made for primary and secondary diagnosis of $\mathrm{BPH}$. Although it is a considerable increase from the number of physician office visits for this condition in 1990s, but the use of surgical procedures for $\mathrm{BPH}$, inpatient hospitalization and length of hospital stay for this have decreased significantly during the same time. This trend is at least partly due to better medical management of $\mathrm{BPH}$. Other factor which has contributed towards this changing trend is the use of minimally invasive therapies.(12)

\section{Watchful waiting}

Watchful waiting is recommended for those men who have mild symptoms (AUA symptom score < or equal to 7) or for those with moderate to severe symptoms (AUA score $>$ or equal to 8) who do not perceive their symptoms as particularly bothersome, and are not experiencing any complications of BPH. (13). In these patients, the risk of treatment, overweight the benefits, and treating these patients is not likely to improve their quality of life. Annual follow up is recommended for these patients for symptom progression. (14) Various treatment options should be discussed with these patients by their health care providersand the patients should be offered various treatment choices. (15)
Int. J. Curr. Res. Biol. Med. (2017). 2(5): 12-19

\section{Lifestyle modifications}

Patients with bothersome LUTS which start affecting the quality of life, are recommended lifestyle modifications, like night time fluid restriction, timed bladder voiding, double voiding techniques, regular physical activities, avoiding caffeinated drinks and alcohol, and treatment of constipation. These lifestyle modifications may prevent or delay the progression of disease to the point of where medical or surgical therapy becomes essential. (16)

\section{Alpha blockers}

Alpha receptors are present on the smooth muscles of prostate, prostatic urethra and the bladder neck. Alpha blockers act by blocking these adrenoceptors, thus acting on dynamic component of $\mathrm{BPH}$, and there by leading to decreasing the muscle tone and reduction in bladder obstruction.(16)

In the 1990s many randomized, double-blind, placebocontrolled showed that finasteride, a 5-ARI, and terazosin, an $\alpha$-blocker, significantly improved LUTS and increased peak urinary flow rates in men with $\mathrm{BPH}$. Based on these reports, medical therapy for BPH was accepted and developed. $(17,18,19)$ Over a period of many years, many strongly structured clinical trials confirmed the effectiveness of five $\alpha$-blockers (terazosin, doxazosin, tamsulosin, alfuzosin, and silodosin) and two 5-ARIs (finasteride and dutasteride). (22)This resulted in all these drugs being approved by the US Food and Drug Administration (FDA) for the treatment of BPH. Alpha blockers are used to treat patients with moderate to severe symptoms of BPH. All clinically Alpha blockers have comparable efficacy. It takes a few hours to a few days to increase urinary flow rate after intake of alpha blockers. $(16,20)$

\section{Non selective alpha blockers}

Phenoxybenzamine is a non selective alpha blocker which blocks both alpha 1 and alpha 2 adrenoceptors. This was the first drug which was studied for treatment of BPH. But because of its non selective blockade of alpha adrenoceptors, the incidence of adverse effect is very high. Hence, it is no longer used for treatment for BPH these days. The 2010 update to AUA guidelines also mentions that there is insufficient evidence for recommending phenoxybenzamine for treatement of LUTS or BPH. (21) 
Alpha-1 receptor blockers

A significant degree of LUTS in BPH occurs due to increased smooth muscle tension at the level of prostatic stroma, urethra and bladder neck. Alpha 1 adrenergic receptors mediate this smooth muscle tension. These receptors are specifically present at bladder neck, urethra and prostate; and not in other tissues. Alfa-1 receptor antagonists are further subdivided into short acting blockers and long acting blockers. Prazocin, alfuzocin and indoramin are short acting blockers; while Terazocin, doxazocin, slow release (SR) alfuzosin are long acting blockers. Doxazocin and terazocin are terrible alpha-blockers. Their efficacy is dose dependent. They are also more likely to show adverse affects at higher doses. The most common adverse effects are orthostatic hypotension, dizziness, fatigue, ejaculatory dysfunction and nasal congestion. (14)The Veterans Affair study (VA study) has confirmed the effectiveness of terazocin, an alfa blocker in relieving LUTS symptoms in BPH patients. In the same study, the effectiveness of finasteride has not been shown to be significantly better than placebo. Moreover, there was no benefit of combination therapy over $\alpha$-blocker monotherapy.(23) The VA study was followed by the PREDICT study, in which doxazosin was used instead of terazosin. This study confirmed the findings of the VA study. In this study too, the Alpha blocker (doxazosin) was proved to be significantly more effective than placebo at relieving LUTS and increasing peak urinary flow rate. (24).

\section{New $\alpha$-Blockers}

Newer $\alpha$-blockers have been developed, some of which are longer-acting, and some are subtypeselective agents. All these changes have resulted in easier dosing regimens and reduced side effects while maintaining the effectiveness. (7). With the development of subtype-selective $\alpha$-antagonists and novel formulations, a single, daily-dose administration without the requirement for dose titration has been made possible.(10). Alpha -antagonists have been divided into three subtypes $\alpha_{1 \mathrm{~A}}, \alpha_{1 \mathrm{~B}}$, and $\alpha_{1 \mathrm{D}}$. The $\alpha_{1 \mathrm{~A}}$ receptors are adrenoceptos $r$ primarily present in the prostate, $\alpha_{1 \text { в }}$ are found mainly in vasculature, and $\alpha_{1 \mathrm{D}^{-}}$ adrenoceptors are present in the bladder and nerve junctions. (25). Silodosin has shown potential for use as selective $\alpha$-adrenoceptor clinically. Silodosin exhibits very high selectivity for $\alpha_{1 \mathrm{~A}}$ versus $\alpha_{1 \mathrm{~B}}$ and modest selectivity for $\alpha_{1 \mathrm{~A}}$ versus $\alpha_{1 \mathrm{D}}$. Studies show that silodosin does not have any cardiovascular adverse effects. However the incidence of ejaculatory dysfunction for silodosin is higher than all other $\alpha$ blockers. $(26,27)$.It has been observed that patients who experience ejaculatory dysfunction also have the greatest efficacy of silodosin. (28). Thus it is a challenge to adjust the dose of silodosin to such a level so that maximum possible efficacy is obtained without getting ejaculatory dysfunction as a side effect.

\section{Phosphodiesterase Type 5 (PDE5) Inhibitors}

There is abundance of nitric oxide staining nerves in prostate. Moreover prostate smooth muscle tension is mediated by NO. (29,30). Laydner and colleagues (29) suggested alternative mechanism of PDE5 inhibitors, including endothelin inactivation, decrease in autonomic hyperactivity, and reduction of pelvic ischemia.

PDE5 inhibitors are safe and efficacious drugs used primarily for the treatment option for ejaculatory dysfunction (ED). (31). Among the commonly available PDE5 inhibitors, tadalafil has the longest half life of 36 hours. Tadalafil, $5 \mathrm{mg}$, is the only drug approved for daily administration for the treatment of ED. This feature makes tadalafil the most promising commercially available PDE5 inhibitor as a once-daily treatment of BPH/LUTS. (31)

Four large, double-blind, placebo-controlled trials have consistently shown the effectiveness of sildenafil, tadalafil, and vardenafil in men with LUTS and BPH. (32-35) All these studies consistently demonstrated that this class of drugs improves LUTS in men with BPH.(35) .

\section{Intraprostatic Botulinum Toxin Type A}

Botulinum toxin type A (BoNT-A) acts irreversibly at acetylcholinergic synapses to block the release of the neurotransmitter acetylcholine. (36) . Preliminary studies demonstrate durable improvements in overactive bladder $(\mathrm{OAB})$ voiding symptoms after cystoscopy-guided injection. (37)

Ilie and colleagues have published the clinical studies investigating BoNT-A for the treatment of LUTS/BPH. BoNT-A is administered using transrectal ultrasound guidance, and injection is performed transperineally, transrectally, or transurethrally. Typically administered doses vary from 100 to 300 units depending on the size of the prostate. The procedure can be performed on an outpatient basis, and there is no need for Folley catheter drainage of the bladder after the procedure. (38) 
ISSN: 2455-944X

Although, very impressive improvements in IPSS, peak flow rates, and prostate volume have been observed, the majority of reported BoNT-A clinical studies in men with LUTS/BPH was from small, single institutions and were not randomized or placebo controlled. (38) One placebo-controlled study demonstrated statistically significant treatment differences in both IPSS and uroflowmetric parameters. (39) Follow-up studies in this same cohort demonstrated durable responses at 12 months and beyond. (40)

\section{NX-1207}

NX-1207 is a new drug under investigation for the treatment of symptomatic BPH. NX-1207 has a proapoptotic effect on the prostate. (41) The drug is injected directly into the prostate as a single dose administration. Four clinical trials have shown improvement in LUTS exceeding that of all other medical therapies currently available for the treatment of BPH. These clinical benefits were maintained after single injection for a year. Phase III studies are underway to define the true efficacy, safety, and mechanism of action of this novel approach to treating BPH. (41)

\section{Gonadotropin-Releasing Hormone (GnRH) Antagonists}

GnRH agonists reduce the volume of $\mathrm{BPH}$ by lowering serum and intraprostatic testosterone and dihydrotestosterone levels. This results in some modest clinical benefits related to improvements in LUTS. The primary disadvantages of GnRH agonists are their associated immediate and long-term adverse effects due to induction of castrate levels of testosterone.

A small, open-label study with the GnRH antagonist cetrorelix acetate demonstrated that short-term administration of the drug was associated with longterm improvement in LUTS and decreased prostate volume. (42) A phase II, randomized, placebocontrolled study in men with BPH/LUTS conducted in Eastern Europe demonstrated promising results. (43) Following this, phase III studies were conducted in the United States and Europe. In the US study, cetrorelix showed no statistically significant benefit in improving IPSS. In addition, the drug did not have a significant effect on peak flow rate or prostate volume versus placebo. (44) This result is in contrast to the favourable results of previous studies. A subsequent multicenter European trial also failed to show any treatment-related efficacy of cetrorelix. (45).
Int. J. Curr. Res. Biol. Med. (2017). 2(5): 12-19

Alpha Reductase Inhibitors(5 ARIs)

The effectiveness of finasteride to control LUTS was proposed by studies conducted in 1990s. $(17,18,19)$ These were confirmed by many randomised controlled trials which were done in the following years. But the VA trial and PREDICT trial failed to show effectiveness of 5 alpha reductase inhibitors as compared to placebo. $(23,24)$

The finasteride registration study, which enrolled men with disproportionately large prostate sizes, showed usefulness of 5 ARIs in controlling LUTS. There was a difference in the design of the VA trial and the fenasteride registration study. Whereas the finasteride registration study was done on a population with very large prostates size (mean prostate size $=58.6 \mathrm{~cm}^{3}$ ), the VA study was conducted on men with BPH irrespective of the prostate size (mean prostate size $=$ $37 \mathrm{~cm}^{3}$ ).

Finasteride and dutasteride supresses prostate growth by inhibiting conversion of testosterone to dihydrotestosterone. (46) Therefore in finasteride registration study it was expected that the subset most likely to respond to a drug whose mechanism of action is to reduce prostate size; and expectantly the study showed that it was most beneficial when size of prostate is $40 \mathrm{ml}$ or greater. (47) Around six month of treatment is required to get clinical relief. (48)

Therefore, the findings of the VA study reflect the effectiveness of the evaluated medical therapies for all men with clinical $\mathrm{BPH}$, whereas the findings of the finasteride registration study only reflect the effectiveness of medical therapy for BPH patients with large prostates.

The prostate cancer prevention trial has shown that the incidence of having high grade cancer is increased in patients receiving finasteride for more than seven years, but overall risk of prostate cancer is decreased in these patients. (49) Moreover, finaseride decreases prostate specific antigen (PSA) levels. So in order to screen patients for prostate cancer using PSA, the levels of PSA should be doubled to negate this effect. (50)

\section{Combination Therapy}

$\alpha$-Blocker and 5-ARI

It has been conclusively proved by various two clinical trials including The VA Cooperative Trial 
ISSN: 2455-944X

(23)and the PREDICT trial (24) that combining a 5ARI with an $\alpha$-blocker does not lead to additional clinical benefits in terms of decreasing LUTS or increase peak urinary flow in patients of BPH. While the VA trial used terazocin as an alpha blocker, the PREDICT trial replaced terazociin with doxazocin. In the PREDICT trial ,the baseline volume of prostate was 36 grams which is very similar to that of the VA study.

The MTOPS trial showed combined effect of alpha inhibitors and 5 alpha reductase inhibitors is more effective than the monotherapy. But, MTOPS study design was very different from the VA study or the PREDICT study(51).

CombAT trial, (52) showed that dutasteride. is is more beneficial than an $\alpha$-blocker. In CombAt trial study group was patients of BPH with large prostates. In fact, the prostate volume in the CombAT trial was $70 \%$ more than the MTOPS trial. In MTOPS trial progression to AUR and BPH surgery showed most favourable results for 5-ARI, so in CombAt trial these two primary end points were used.

The Symptom Management After Reducing Therapy (SMART-1) trial by Barkin and colleague (53) did a placebo controlled trial in which 327 men with $\mathrm{BPH}$ with large prostate sizes (volume exceeding $30 \mathrm{~cm}^{2}$ ). They were first treated with combination therapy using datasteride and tamsulosin for 2 years. After that there was randomised placebo controlled withdrawal of tamsulosin for 1 year. There was worsening of LUTS in $23 \%$ of study population after withdrawal of tamsulosin, while $9 \%$ reported worsening of LUTS in which both drugs were continued. When we compared men with severe LUTS at the start of study, this difference was even more remarkable. $42.5 \%$ of men reported worsening of symptoms when tamsulosin was withdrawn as compared to $14 \%$ of the men who reported worsening of LUTS where both drugs were continued.

\section{Conclusion}

$\mathrm{BPH}$ is a common disease of old men, which has a great impact on quality of life and health care costs. The medical treatment of BPH has improved over the past many years. Two treatment options are widely used in management of $\mathrm{BPH}$, either monotherapy with alpha blockers, or combined therapy with an alpha blocker and a 5 ARI. Both these treatment options have been shown to slower down the disease progression and give symptomatic improvement, but
Int. J. Curr. Res. Biol. Med. (2017). 2(5): 12-19

the data is more robust in case of alpha blocker monotherapy. The research suggests that the patients with LUTS due to BPH should be treated with alpha blockers as a first choice. Although, in patients of BPH with large prostates, the combination therapy with alpha blockers and 5 ARIs have been proven to be superior to monotherapy with alpha blockers in preventing AUR and BPH surgery, and also in decreasing LUTS; but higher costs and higher number of patients needed to treat in order to prevent disease progression in a single patient are some of the concerns which makes combination therapy in clinical setting less useful in general. This is especially true considering the long term medical treatment which is needed for this disease. In case of newer therapies like NX-1207 and GNRH agonists, phosphodiestrase type 5 inhibitors, and Intraprostatic toxin type- A injections, although initial studies seem very encouraging, more research is needed in order to widely use these treatment options in cases of BPH.

\section{Source of funding: Nil}

Conflict of interest: None declared

\section{References}

1. Arrighi HM, Metter EJ, Guess HA, Fozzard JL. Natural history of benign prostatic hyperplasia and risk of prostatectomy. The Baltimore Longitudinal Study of Aging. Urology. 1991;38(1 suppl):4-8

2. American Urological Association. Guideline on the management of benign prostatic hyperplasia (BPH). http://www.auanet.org/guidelines/bph.cfm. Accessed September 19, 2007.

3. Roehrborn CG. Benign prostatic hyperplasia: an overview. Rev Urol. 2005: 7 (Suppl 9): S3-S14.

4. Shapiro E, Becich MJ, Hartanto V, Lepor H. The relative proportion of stromal and epithelial hyperplasia is related to the development of symptomatic benign prostate hyperplasia. J Urol. 1992;147:1293-1297.

5. Cotran RS, Kumar V, Robbins SL. Male genital system. In: Robbins Pathologic Basis of Disease. 5th ed. Philadelphia, Pa.: Saunders; 1994.

6. Nickel JC, Mendez-Probst CE, Whelan TF, et al. 2010 update: Guidelines for management of benign prostatic hyperplasia. Can Uro Assoc J. 2010; $\quad 4:$ 310-6. http://www.cua.org/themes/web/assets/files/guideli nes/en/guidelines_for_the_management_of_benign _prostatic.pdf 
ISSN: 2455-944X

7. Lepor H. Pathophysiology, epidemiology, and natural history of benign prostatic hyperplasia. Rev Urol. 2004;6(suppl 9):S3-S10. - See more at: https://www.uspharmacist.com/article/guidelinesfor-the-treatment-of-benign-prostatichyperplasia\#sthash.fkvDmvnN.dpuf

8. Parsons JK, Bergstrom J, Barrett-Connor E. Prevelence and chracteristics of lower urinary tract infections in men > or $=80$ years. Urology. 2008; 72: 318-321.

9. Caine M. The present role of alpha-adrenergic blockers in the treatment of benign prostatic hypertrophy. J Urol. 1986;136:1-6.

10. Lepor H. Pathophysiology of Benign Prostatic Hyperplasia in the Aging Male Population. Rev Urol. 2005; 7(Suppl 4): S3-S12.

11. Taylor BC, Wilt TJ, Fink HA, Lambert LC, Marshall LM et al. Prevalence, severity, and health correlates of lower urinary tract symptoms among older men: The MrOS study. Urology, Volume 68 , Issue 4, 804 - 809.

12. Wei JT, Calhoun E, Jaccobsen SJ. Urologic diseases in American project: benign prostatic hyperplasia. J Urol. 2005: 173: 1256-61.

13. Logan YT, Belgeri MT. Monotherapy versus combination drug therapy for the treatment of benign prostatic hyperplasia. Am $\mathrm{J}$ Geriatr Pharmacother. 2005;3(2):103-114.

14. Benign Prostatic Hypertrophy Treatment \& Management: Approach Considerations, Combination Therapy, Phytotherapeutic Agents and Dietary Supplements. 2017 May 3 [cited 2017 May 14]; Available from: http://emedicine.medscape.com/article/437359treatment

15. McVary KT, Roehrborn CG, Avins AL, et al. American Urological Association Guideline: Management of Benign Prostatic Hyperplasia (BPH). Linthicum, MD: American Urological Association; 2010:1-62, Appendix 278-285.

16. Fonseca J, Martins da silva C. The diagnosis and treatment of lower urinary tract symptoms due to benign prostatic hyperplasia with $\alpha$-blockers: focus on silodosin. Clin Drug Investig. 2015;35:7-18.

17. The Finasteride Study Group, authors. Finasteride (MK-906) in the treatment of benign prostatic hyperplasia. Prostate. 1993;22:291-299.

18. Lepor H, Auerbach S, Puras-Baez A, et al. A randomized, placebo-controlled multicenter study of the efficacy and safety of terazosin in the treatment of benign prostatic hyperplasia. J Urol. 1992;148:1467-1474.
Int. J. Curr. Res. Biol. Med. (2017). 2(5): 12-19

19. Lepor H. Nonoperative management of benign prostatic hyperplasia. J Urol. 1989;141:1283-1289.

20. Wang X, Wang X, Li S, et al. Comparative effectiveness of oral drug therapies for lower urinary tract symptoms due to benign prostatic hyperplasia: a systematic review and network meta-analysis. PLoS One. 2014;9(9):e107593 - See more at: https://www.uspharmacist.com/article/guidelinesfor-the-treatment-of-benign-prostatichyperplasia\#sthash.AdtgmP4k.dpuf

21. McVary KT, Roehrborn CG, Avins AL, Barry MJ, Bruskewitz RC, Donnell RF, et al. Update on AUA Guideline on the Management of Benign Prostatic Hyperplasia. J Urol. 2011 Mar 17. [Medline].

22. Kirby R, Lepor H. Evaluation and nonsurgical management of benign prostatic hyperplasia. In: Wein AJ, Kavoussi LR, Novick AC, editors. Campbell-Walsh Urology. 9th ed. New York: Elsevier; 2007. pp. 2766-2782.

23. Lepor H, Williford WO, Barry MJ, et al. The efficacy of terazosin, finasteride, or both in benign prostatic hyperplasia. Veterans Affairs Cooperative Studies Benign Prostatic Hyperplasia Study Group. N Engl J Med. 1996;335:533-539.

24. Kirby RS, Roehrborn C, Boyle P, et al. for the Prospective European Doxazosin and Combination Therapy Study Investigators, authors. Efficacy and tolerability of doxazosin and finasteride, alone or in combination, in treatment of symptomatic benign prostatic hyperplasia: the Prospective European Doxazosin and Combination Therapy (PREDICT) trial. Urology. 2003;61:119-126. [PubMed]

25. Schwinn DA, Roehrborn CG. Alpha1adrenoceptor subtypes and lower urinary tract symptoms. Int J Urol. 2008; 15:193-199.

26. Lepor H, Hill LA. Silodosin for the treatment of benign prostatic hyperplasia: pharmacology and cardiovascular tolerability. Pharmacotherapy. 2010;30:1303-1312.

27. Marks LS, Gittelman MC, Hill LA, et al. Rapid efficacy of the highly selective alpha1Aadrenoceptor antagonist silodosin in men with signs and symptoms of benign prostatic hyperplasia: pooled results of 2 phase 3 studies. J Urol. 2009; 181:2634-2640.

28. Roehrborn CG, Lepor H, Kaplan SA. Retrograde ejaculation induced by silodosin is the result of relaxation of smooth musculature in the male urogenital tracts and is associated with greater urodynamic and symptomatic improvements in men LUTS secondary to BPH. J Urol. 2009;181:694-695. [Abstract 1922] 
ISSN: 2455-944X

29. Laydner HK, Oliveira P, Oliveira CR, et al. Phosphodiesterase 5 inhibitors for lower urinary tract symptoms secondary to benign prostatic hyperplasia: a systematic review. BJU Int. 2011;107:1104-1109.

30. Takeda M, Tang R, Shapiro E, et al. Effects of nitric oxide on human and canine prostates. Urology. 1995;45:440-446.

31. Dorsey P, Keel C, Klavens M, Hellstrom WJ. Phosphodiesterase type 5 (PDE5) inhibitors for the treatment of erectile dysfunction. Expert Opin Pharmacother. 2010;11:1109-1122.

32. McVary KT, Monnig W, Camps JL, Jr, et al. Sildenafil citrate improves erectile function and urinary symptoms in men with erectile dysfunction and lower urinary tract symptoms associated with benign prostatic hyperplasia: a randomized, double-blind trial. J Urol. 2007;177:1071-1077.

33. McVary KT, Roehrborn CG, Kaminetsky JC, et al. Tadalafil relieves lower urinary tract symptoms secondary to benign prostatic hyperplasia. J Urol. 2007;177:1401-1407.

34. Stief CG, Porst H, Neuser D, et al. A randomised, placebo-controlled study to assess the efficacy of twice-daily vardenafil in the treatment of lower urinary tract symptoms secondary to benign prostatic hyperplasia. Eur Urol. 2008;53:12361244

35. Roehrborn CG, McVary KT, Elion-Mboussa A, Viktrup L. Tadalafil administered once daily for lower urinary tract symptoms secondary to benign prostatic hyperplasia: a dose finding study. J Urol. 2008;180:1228-1234.

36. Schantz EJ, Johnson EA. Botulinum toxin: the story of its development for the treatment of human disease. Perspect Biol Med. 1997;40:317-327.

37. Nitti VW. Botulinum toxin for the treatment of idiopathic and neurogenic overactive bladder: state of the art. Rev Urol. 2006;8:198-208.

38. Ilie CP, Chancellor MB, Chuang YC, Dan M. Intraprostatic botulinum toxin injection in patients with benign prostatic enlargement. J Med Life. 2009;2:338-342. [PMC free article] [PubMed]

39. Maria G, Brisinda G, Civello IM, et al. Relief by botulinum toxin of voiding dysfunction due to benign prostatic hyperplasia: results of a randomized, placebo-controlled study. Urology. 2003;62:259-264.

40. Brisinda G, Cadeddu F, Vanella S, et al. Relief by botulinum toxin of lower urinary tract symptoms owing to benign prostatic hyperplasia: early and long-term results. Urology. 2009;73:90-94.
Int. J. Curr. Res. Biol. Med. (2017). 2(5): 12-19

41. Shore N. NX-1207: a novel investigational drug for the treatment of benign prostatic hyperplasia. Expert Opin Investig Drugs. 2010;19:305-310.

42. Gonzalez-Barcena D, Vadillo Buenfil, Garcia Procel E, et al. Inhibition of luteinizing hormone, follicle-stimulating hormone and sex-steroid levels in men and women with a potent antagonist analog of luteinizing hormone-releasing hormone, Cetrorelix (SB-75) Eur J Endocrinol. 1994;131:286-292.

43. Debruyne F, Tzvetkov M, Altarac S, Geavlete PA. Dose-ranging study of the luteinizing hormonereleasing hormone receptor antagonist cetrorelix pamoate in the treatment of patients with symptomatic benign prostatic hyperplasia. Urology. 2010;76:927-933.

44. AEterna Zentaris (AEZS) announces results from two phase 3 studies with cetrorelix in benign prostatic hyperplasia, phase 3 trial misses primary endpoint [press release] Quebec City, Canada: AEterna Zentaris; 2009.

45. AEterna Zentaris (AEZS) announces results from its European phase 3 study with cetrorelix in benign prostatic hyperplasia; study Z-036 did not reach primary endpoint [press release] Quebec City, Canada: AEterna Zentaris; 2009

46. McNaughton-Collins M, Barry MJ. Managing patients with lower urinary tract symptoms suggestive of benign prostatic hyperplasia. Am J Med. 2005;118(12):1331-1339.

47. Roehrborn CG, Boyle P, Bergner D, et al., for the PLESS Study Group. Serum prostate-specific antigen and prostate volume predict long-term changes in symptoms and flow rate: results of a four-year, randomized trial comparing finasteride versus placebo. Urology. 1999;54(4):662-669.)

48. Logan YT, Belgeri MT. Monotherapy versus combination drug therapy for the treatment of benign prostatic hyperplasia. Am J Geriatr Pharmacother. 2005;3(2):103-114.

49. Civantos F, Soloway MS, Pinto JE. Histopathological effects of androgen deprivation in prostatic cancer. Semin Urol Oncol. 1996;14(2 suppl 2):22-31.

50. Andriole GL, Guess HA, Epstein JI, et al. Treatment with finasteride preserves usefulness of prostate-specific antigen in the detection of prostate cancer: results of a randomized, double-blind, placebo-controlled clinical trial. PLESS Study Group. Proscar Long-term Efficacy and Safety Study. Urology. 1998;52(2):195-201. 
51. McConnell JD, Roehrborn CG, Bautista OM, et al. for the Medical Therapy of Prostatic Symptoms (MTOPS) Research Group, authors. The long-term effect of doxazosin, finasteride, and combination therapy on the clinical progression of benign prostatic hyperplasia. N Engl J Med. 2003;349:2387-2398.

52. Roehrborn CG, Siami P, Barkin J, et al. for the CombAT Study Group. The effects of combination therapy with dutasteride and tamsulosin on clinical outcomes in men with symptomatic benign prostatic hyperplasia: 4-year results from the CombAT study. Eur Urol. 2010;57:123-131.

53. Barkin J, Guimarães $M$, Jacobi $G$, et al. Alphablocker therapy can be withdrawn in the majority of men following initial combination therapy with the dual 5alpha-reductase inhibitor dutasteride. Eur Urol. 2003;44:461-466.

\begin{tabular}{|c|c|}
\hline \multicolumn{2}{|c|}{ Access this Article in Online } \\
\hline 口栜好品 & $\begin{array}{l}\text { Website: } \\
\text { www.darshanpublishers.com }\end{array}$ \\
\hline 夏徒势 & $\begin{array}{l}\text { Subject: } \\
\text { Medicine }\end{array}$ \\
\hline $\begin{array}{l}\text { Quick Response } \\
\text { Code }\end{array}$ & \\
\hline
\end{tabular}

How to cite this article:

N.S. Neki, Jaswinder Singh. (2017). Medical management of Benign Prostate Hyperplasia: New insights. Int. J. Curr. Res. Biol. Med. 2(5): 12-19.

DOI: http://dx.doi.org/10.22192/ijcrbm.2017.02.05.003 